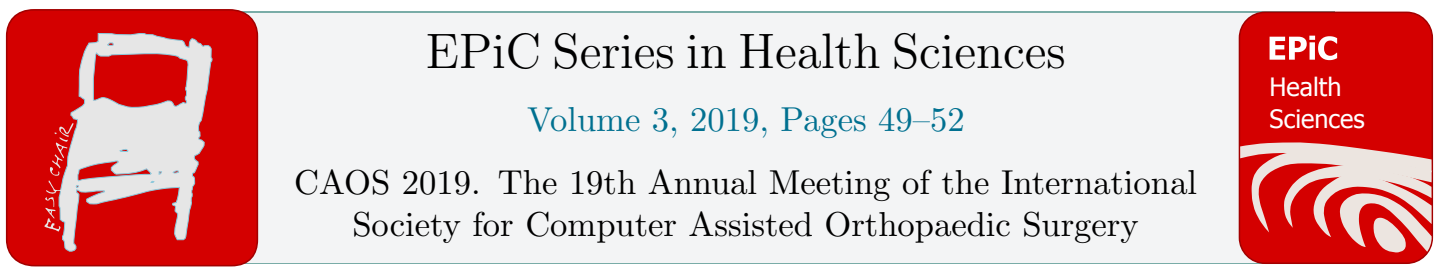

\title{
The Learning Curve and Alignment Assessment of an Image-Free Handheld Robot in TKA: the First Patient Series in Europe
}

\author{
P. Bollars ${ }^{1}$, A, Boeckxstaens ${ }^{1}$, J. Mievis ${ }^{1}$ and D. Janssen ${ }^{1}$. \\ ${ }^{1}$ St Trudo Hospital, Sint Truiden, Belgium \\ Peter.Bollars@stzh.be, Anton.Boeckxstaens@stzh.be,Jan.Mievis@stzh.be, \\ Daniel.Janssen@stzh.be
}

\begin{abstract}
Total knee arthroplasty (TKA) is the gold standard for patients with end-stage knee osteoarthritis, with excellent clinical results. It provides pain relief, enhanced mobility, and improved quality of life. Yet, 20\% of patients remain dissatisfied (Bourne RB, 2009). Well-known reasons for early failure are instability, implant malpositioning, and limb malalignment. The typical objective of TKA is to obtain a neutral mechanical axis of the leg. Deviation of more than 3 degrees from a neutral mechanical axis is associated with increased failure rates due to off-axis loading, polyethylene wear and subsequent implant loosening (Bargren JH, 1983) (Jeffery RS, 1991) (Lotke PA, 1977) (Ritter MA, 1994) (Mason JB, 2007) [2-6]. The introduction of robotics aims to reduce technical errors and optimize implant position.

In April 2018, the NAVIO® Surgical System (Smith \& Nephew, Pittsburgh, PA, USA) was introduced in the St.-Trudo hospital in Sint-Truiden, Belgium. This hospital is the first in Europe to use this robotic system for TKA. NAVIO enables the surgeon to plan the implant position in six degrees of freedom intraoperatively without the need for a preoperative imaging. Intra-operative adjustments allow the surgeon to optimize softtissue balance. Implant placement accuracy of this image-free approach has been demonstrated through cadaveric studies (Lonner JH, 2010) (Smith JR, 2014). However, there is lack of clinical studies in patients receiving a TKA with the NAVIO system. This is the first clinical study in Europe that presents the early results of the use of NAVIO in TKA.
\end{abstract}

\section{Introduction}


NAVIO TKA: the First Patient Series in Europe P. Bollars, A Boeckxstaens, J. Mievis, D. Janssen

The aim of this study is to analyze the limb alignment in the coronal plane after TKA implantation with the use of NAVIO, including the amount of outliers, defined as a deviation of more than 3 degrees from a neutral mechanical axis. Also the learning curve of the NAVIO Surgical System in patients undergoing TKA is presented in this study.

\section{Material and methods}

The first sixty-nine patients who underwent TKA with the NAVIO system by two experienced surgeons (PB, JM) were included in this study. The JOURNEY II BiCruciate Stabilized (BCS) Total Knee System implant was used in all cases. Pre- and postoperative mechanical limb alignment and balancing was measured by the NAVIO system.

Registration time, planning time and cutting time was monitored peri operative by the NAVIO ${ }^{\mathrm{TM}}$ system. All data was analyzed retrospectively.

\section{Results}

The mean age of the patients was 68.2 years (SD 9.9). $48 \%$ of the patients were female and the Kellgren Lawrence scale was grade I in 5\%, grade II in 6\%, grade III in $49 \%$ and grade IV in $16 \%$.

The mean preoperative mechanical limb alignment was $3.18^{\circ}$ varus (SD $4.28^{\circ}$, range $15.08^{\circ}$ varus to $4.30^{\circ}$ of valgus). The mean intraoperative planned angle was $0.59^{\circ}$ varus (SD $0.97^{\circ}$, range $2.50^{\circ}$ varus to $0.99^{\circ}$ valgus). The mean postoperative alignment was $1.17^{\circ}$ varus $\left(\mathrm{SD} 1.78^{\circ}\right.$, range $4.52^{\circ}$ varus to $4.33^{\circ}$ valgus.

The mean postoperative alignment of $1.17^{\circ}$ varus did not vary in time due to the learning curve.

The amount of outlayers (deviation of more than $3^{\circ}$ of the neutral axis) is $4 \%$ in this study.

The mean surgical time was $105.3 \mathrm{~min}$ (SD 16.3). The mean extra surgical time (EST) for registration and planning decreased from $23.4 \mathrm{~min}$ (SD 3.7 $\mathrm{min}$ ) to $13.2 \mathrm{~min}$ (SD 2.0) throughout the learning curve with a range of $10 \mathrm{~min} 05 \mathrm{sec}$ to $28 \mathrm{~min} 19 \mathrm{sec}$.

\section{Discussion}

The typical aim for TKA is to obtain a neutral mechanical axis. Deviation from this axis is associated with increased failure rates and decreased survival (Fehring TK, 2001). Therefore, it is of utmost importance to achieve a neutral mechanical axis with few statistical outliers and technical errors. Our results show that the NAVIO system can reduce technical errors by providing intraoperative information and feedback about the implant position to the surgeon. It provides the surgeon with full control of implant positioning as well as ligamentous balancing throughout the procedure. In our series we achieved a mean postoperative limb alignment of $1.17^{\circ}$ varus compared to a planned alignment of $0.59^{\circ}$ varus.

In comparing to literature, we found a low amount of outlayers in the coronal plane by using the NAVIO robotic system of $4 \%$ (Boonen B, 2013) (Hetailish BM, 2012). 
NAVIO TKA: the First Patient Series in Europe P. Bollars, A Boeckxstaens, J. Mievis, D. Janssen

Operative time is expected to be longer with the use of the NAVIO robotic system. The mean EST as calculated by the sum of the registration time and planning time decreased from $23 \mathrm{~min}$ to $13 \mathrm{~min}$ throughout the learning curve over a duration of 7 months. Prolonged operative time is correlated with increased infection rates after TKA (Peersman G, 2006). This study shows the importance of a fast learning curve to reduce operative time when using NAVIO.

\section{Conclusion}

The NAVIO robotic system is a valuable tool in assisting total knee arthroplasty. It allows the surgeon to accurately determine optimal implant position for each patient and minimize statistical outliers in alignment. There was no difference in postoperative limb alignment throughout the learning curve. We conclude that the NAVIO robotic system is a precise tool which minimizes technical errors. A rapid learning curve can allow for future wide-spread adoption in TKA. Further studies are needed to examine clinical outcomes in patients receiving TKA with the NAVIO system as compared to conventional TKA. The goal by decreasing the amount of outlayers is successful, with less than $5 \%$ of the neutral axis. 


\section{References}

Bargren, JH, Blaha, JD, Freeman, MA (1983) Alignment in total knee arthroplasty. Correlated biomechanical and clinical observations. Clin Orthop Relat Res:178-183

Boonen, B, Schotanus, MG, Kerens, B, van der Weegen, W, van Drumpt, RA, Kort, NP (2013). Intra-operatieve results and radiological outcome of conventional and patient-specific surgery in total knee arthroplasty: a multicenter, randomized controlled trial. Knee Surg Sports Traumatol Arthrosc. 21 (10): 2206-12

Bourne, RB, Chesworth, BM, Davis, AM, Mahomed, NN, Charron, KD. (2009). Patient satisfaction after total knee arthroplasty: who is satisfied and who is not?. Clinical orthopaedics and related research, 468(1), 57-63.

Fehring, TK, Odum, S, Griffin, WL, Mason, JB, Nadaun, M (2001) Early failures in total knee arthroplasty. Clin Orthop Relat Res (392):315-8

Hetailish, BM, Khan, MM, Simunovic, N, Al-Harbi, HH, Bhandari, M, Zalzal, PK (2012). Metaanalysis of navigation vs conventional total knee arthroplasty. J Arthroplasty, 27 (6): 1177-82

Jeffery, RS, Morris, RW, Denham, RA (1991) Coronal alignment after total knee replacement. J Bone Joint Surg Br 73:709-714

Lonner, JH, John, TK, Conditt, MA (2010) Robotic arm-assisted UKA improves tibial component alignment: a pilot study. Clin Orthop Relat Res 468:141-146.

Lotke, PA, Ecker, ML (1977) Influence of positioning of prosthesis in total knee replacement. J Bone Joint Surg Am 59:77-79

Mason, JB, Fehring, TK, Estok, R, Banel, D, Fahrbach, K (2007) Meta-analysis of alignment outcomes in computer-assisted total knee arthroplasty surgery. J Arthroplasty 22:1097-1106.

Peersman, G., Laskin, R., Davis, J., Peterson, MG, Richart, T. (2006). Prolonged operative time correlates with increased infection rate after total knee arthroplasty. HSS journal : the musculoskeletal journal of Hospital for Special Surgery, 2(1), 70-2

Ritter, MA, Faris, PM, Keating, EM, Meding, JB (1994) Postoperative alignment of total knee replacement. Its effect on survival. Clin Orthop Relat Res:153-156

Smith, JR, Riches, PE, Rowe, PJ (2014) Accuracy of a freehand sculpting tool for unicondylar knee replacement. Int J Med Robot 10:162-169. 